\title{
Uncertainty and Dark Optimism: A Sociological Account of Youth and the Promise of Higher Education in Post-Truth Era
}

\section{Book Review of: Black, R., \& Walsh, L. (2019): Imagining Youth Futures: University Students in Post-truth Times. Singapore: Springer}

\section{Babak Dadvand ${ }^{1}$ (i)}

Received: 3 May 2020 / Revised: 3 May 2020 / Accepted: 14 May 2020 /

Published online: 5 June 2020

(C) Springer Nature Singapore Pte Ltd. 2020

In their book, Imagining Youth Futures: University Students in Post-Truth Times, Rosalyn Black and Lucas Walsh provide a rich and nuanced account of what it means to live the life of a young university student in the context of rapid social, political and economic transformations. The discussions happen in the backdrop of two contemporary developments impacting youth. First is what the authors describe as 'the spectre of uncertainty' caused by rapid social, economic and political changes that have taken place over the past few decades. The second backdrop to the discussions in the book is the rise of 'post-truth politics' whereby objective facts have lost, at least in part, their currency and instead individual beliefs and personal opinions have taken hold in political debates and matters of public interest.

A key focus of the book is 'the promise of higher education' for young people which, as the authors point out, has become akin to a post-truth promise given increasing uncertainties in young people's transitions beyond formal education. The book engages with accounts from interviews conducted with a cohort of 30 undergraduate and graduate university students from Australia, France and the UK. These are 'the missing middle' and the 'ordinary' young people who have slipped through the cracks in youth studies because of a pre-occupation in research with studies of young people on the margins (see Roberts, 2011).

The book provides a rich account of how university students are constructed, regulated and governed through wider social, political and economic discourses. Youth agency is central to the discussion, and adequate attention is given to how young people

Babak Dadvand

babak.dadvand@unimelb.edu.au

1 Melbourne Graduate School of Education, The University of Melbourne, 100 Leicester Street,

Parkville, Victoria 3010, Australia 
negotiate and respond to prevailing discourses that are predicated upon and constitutive of a particular form of subjectivity, one that is entrepreneurial (Kelly, 2006) and remains in a constant state of calculation in responding to risk and uncertainties. This is reflected in the definition of youth upon which much of the discussions in the book is centred: young university students as what Black and Walsh call 'Homo promptus' who 'is entrepreneurial and strategic, is expected to constantly plan for the future while living life in the short-term, is not tethered to a single place, is permanently in 'situational' mode, and lives in waithood' (p. 9).

The book interrogates 'the empty promise' of higher education, despite its affective appeal tied to hopes and future plans of many young people. Using intimate accounts from the participants, the authors demonstrate the impact of credential inflation on youth who are encouraged to add to their accumulated human, social, cultural and economic capitals to maintain a competitive edge in an increasingly precarious labour market. The young people that we hear from face shared challenges and promises brought about by the massification of higher education and increasing cross-national mobilities. The recurring theme, despite differences in experiences, is the active role young people take to construct their lives and their subjecthood as an 'enterprise' (McNay, 2009).

The book pays due attention to how young people navigate the fluid, complex and multidimensional relationships of contemporary family life. Narratives from the participants demonstrate that far from losing its significance, families have gained increased relevance as a source of social, emotional and material support in navigating uncertainty, something that has already been shown in other research (Wyn et al., 2010). The authors highlight this further for the cohort of university students demonstrating that while these young people build their decisions on the promise of 'meritocracy', they rely on the resources made available to them by their parents and families to navigate the uncertain landscape of contemporary society in pursuit of their goals and 'imagined futures'.

The book also attends to the changes in the labour market and economy, offering intimate accounts about the experiences of young people faced with economic downturns, technological disruptions and emergence of flexible and gig economies. Despite growing uncertainties, an overwhelming majority of the participants pursue the prospect of (an imagined) career rather than a short-lived job. A sense of purpose to contribute through one's career, despite the need for constant flexibility and adaptability to the requirements of a fast-changing labour market, is a recurrent theme. Demise of objective facts and the emergence of post-truth politics is also the topic of discussion. Young people's political engagement, the authors maintain, reflects that of the homo promptus, characterised by scepticism of conventional political processes, and interest in alternative and cause-oriented modes of participation at local and global levels. The discussions here go beyond the convenient construction of youth as either 'engaged' or 'disengaged' and instead tease out the more complex ways through which young university students navigate politics and the public sphere.

Overall, the tales told of young university students in the book reveal cohabitation of hope, aspirations and optimism with pessimism, despair and anxiety; these tales showcase how young people work within and against the emerging social, economic and political discourses to craft their lives in the present and curate themselves towards their imagined futures which has become fraught with risk, uncertainty and ambiguity. 
The tale of these young people, as the authors aptly remind us, is one of the 'youth in waithood' whereby the traditional markers of adulthood such as secure employment, family formation and home ownership have slipped further and further away.

The book makes significant contributions to debates in the field of youth studies; it addresses questions with which sociologists and political theorists have grappled for many years, namely, questions about youth subjecthood and agency at a time when the notion of nationhood has been reimagined, economic laws have been reframed, transnational migration has been expanded and civil societies have been transformed (Beck \& Levy, 2013). By addressing these issues, the authors make significant inroads into debates about risk society teasing out how recent changes have impacted young peoples' experiences, hopes, aspirations, imaginations and above all their sense of self and subjecthood.

Imagining Youth Futures: University Students in Post-Truth Times cannot be any more pertinent than now. At the time of writing this review, many of the issues discussed in the book have come front and centre with the COVID-19 pandemic. The pandemic has sent many businesses into mandatory shutdown to protect public health. The implication of this has been large-scale and historic job losses well beyond the 2007-2008 Global Financial Crisis and unseen since the Great Depression of the 1920s. Amidst all these, young people have been most adversely affected as they constitute the majority of casual workforce or those working in industries hit hardest by the pandemic (Coates, Cowgill, Chen, \& Mackey, 2020). University shutdowns have also furthered the spectre of uncertainty faced by many young people.

Rosalyn Black and Lucas Walsh have helped advance scholarship in the field of youth studies. They have reminded us of the extremely complex and vexed landscape of youth in the current context of ever-growing uncertainties across many contemporary societies. While the authors raise and address questions pertinent to youth scholars, other questions still remain pointing to the need for further attention to issues of subjectivity, resistance, responsibility and agency across various geographical contexts at a time when the promises of higher education, mobility and employment have become ever more uncertain due to the massive, and mostly likely long term, disruptions caused by COVID-19.

\section{References}

Beck U, Levy D (2013) Cosmopolitanized nations: re-imagining collectivity in world Risk Society. Theory, Culture \& Society 30(2):3-31. https://doi.org/10.1177/0263276412457223

Coates B, Cowgill M, Chen T, Mackey W (2020) Shutdown: estimating the COVID-19 employment shock. Grattan Institute, Melbourne, Victoria

Kelly P (2006) The entrepreneurial self and 'youth at-risk': exploring the horizons of identity in the twentyfirst century. J Youth Stud 9(1):17-32

McNay L (2009) Self as enterprise: dilemmas of control and resistance in Foucault's The Birth of Biopolitics. Theory, Culture Soc 26(6):55-77

Roberts S (2011) Beyond 'NEET' and 'tidy' pathways: considering the 'missing middle' of youth transition studies. J Youth Stud 14(1):21-39

Wyn, J., Cuervo, H., Smith, G., \& Woodman, D. (2010). Young people negotiating risk and opportunity: postschool transitions 2005-2009. Melbourne Graduate School of Education, University of Melbourne, Parkville, Victoria 